\title{
Morphological Features and Plaque Composition in Culprit Atheromatous Plaques of Patients with Acute Coronary Syndromes
}

\author{
Tiberiu Nyulas ${ }^{1,2}$, Emese Marton ${ }^{2}$, Victoria Ancuta Rus ${ }^{3}$, Nora Rat ${ }^{1,2}$, Mihaela Ratiu ${ }^{4}$, \\ Theodora Benedek ${ }^{1,2}$, Imre Benedek ${ }^{1,2}$ \\ ${ }^{1}$ Clinic of Cardiology, University of Medicine and Pharmacy, Tîrgu Mureș, Romania \\ ${ }^{2}$ Cardiac Critical Care Unit, Clinic of Cardiology, County Clinical Emergency Hospital, Tîrgu Mureș, Romania \\ ${ }^{3}$ Department of Biostatistics and Informatics, University of Medicine and Pharmacy, Tîrgu Mureș, Romania \\ 4 Biostatistics Center of Advanced Research in Multimodal Cardiac Imaging, Cardio Med Medical Center, Tîrgu Mureș, Romania
}

\section{ABSTRACT}

Background: The independent role of each plaque feature in relation to plaque vulnerability is still the subject of ongoing research. This study aimed to compare the morphologic characteristics of vulnerable atheromatous coronary plaques with the ones of stable, non-vulnerable plaques, and in plaques with different locations in the coronary tree, in order to identify the most relevant imaging-based biomarkers associated with coronary plaque vulnerability. Material and methods: This was a prospective observational, non-randomized study that included 50 patients with unstable angina who underwent computed tomography angiography for assessment of the entire coronary artery tree followed by complex morphologic analysis of all lesions, divided into two groups: group 1 - 25 patients with vulnerable plaque (VP) and group $2-25$ age- and gender-matched patients with non-vulnerable plaque (NVP). Results: Lesions with a stenosis degree $>70 \%$ were significantly longer than those with a stenosis degree $<70 \%$ $(8.27 \pm 2.74 \mathrm{~mm}$ vs. $5.56 \pm 4.11 \mathrm{~mm}, \mathrm{p}=0.04)$. VP presented significantly higher values of plaque thickness ( $\mathrm{p}=0.0005)$, plaque burden $(\mathrm{p}=0.0004)$, and higher total plaque volume $(\mathrm{p}=0.0005)$ than NVP. The remodeling index was not significantly different between the groups $(p=0.6)$, but the eccentricity index was $(0.24 \pm 0.14$ compared to $0.14 \pm 0.17, p=0.023)$. Linear regression analysis revealed a significant correlation between plaque burden and plaque components in VP $(\mathrm{r}=0.76, \mathrm{p}<0.0001$ for necrotic core; $\mathrm{r}=0.62, \mathrm{p}=0.0008$ for fibro-fatty tissue; and $\mathrm{r}=0.5, \mathrm{p}$ $=0.01$ for fibrotic tissue volume). Culprit plaques located in the right coronary artery presented significantly larger plaque burden volumes $\left(91.17 \pm 4.88 \mathrm{~mm}^{3} \mathrm{vs} .83 .35 \pm 8.47 \mathrm{~mm}^{3}, \mathrm{p}=0.04\right)$, larger volumes of necrotic core $\left(82.03 \pm 47.85 \mathrm{~mm}^{3}\right.$ vs. $\left.45.84 \pm 43.72 \mathrm{~mm}^{3}, \mathrm{p}=0.02\right)$ and fibrofatty tissue $\left(53.23 \pm 31.92 \mathrm{~mm}^{3}\right.$ vs. $\left.23.76 \pm 20.90 \mathrm{~mm}^{3}, \mathrm{p}=0.02\right)$ than the ones situated in the left coronary artery. Conclusions: VPs from the culprit lesions exhibit a different phenotype than non-vulnerable ones, and vulnerability features are present in a significantly larger extent in VPs from the right coronary artery as compared to those from the left coronary artery.

Keywords: atheromatous plaque, vulnerability, morphologic characteristics, acute coronary syndrome

\section{ARTICLE HISTORY}

Received: August 15, 2017

Accepted: April 17, 2018

\section{CORRESPONDENCE}

\section{Emese Marton}

Str. Gheorghe Marinescu nr. 50

540136 Tîrgu Mureș, Romania

Tel: +40265212 111

E-mail: emese.marton92@gmail.com 


\section{INTRODUCTION}

Acute coronary syndromes (ACSs) continue to represent a major cause of mortality worldwide, being responsible for the highest number of deaths in developed countries., ${ }^{1,2}$ In most of the cases, ACSs are produced by the rupture or the erosion of a coronary plaque, an atheromatous lesion that becomes suddenly unstable. The lesion that caused an acute coronary event is called "the culprit lesion", in order to be differentiated from other co-existing lesions present in the coronary tree, with a more stable phenotype, which are not responsible for the ACS. ${ }^{3-8}$

It has been well demonstrated that transformations of plaque composition into a more vulnerable phenotype precedes plaque rupture. ${ }^{8}$ This fact has a tremendous clinical relevance, as plaque composition can be easily assessed nowadays, due to the significant advances in imaging technologies. The identification of a vulnerable plaque (VP) in the coronary arteries can serve for the timely initiation of different strategies to prevent plaque progression, rupture, or erosion, either by using interventional treatment, or by initiating optimum medical therapy. ${ }^{9,10}$

Image-based characterization of a VP is based on the identification of features of vulnerability inside the plaque, features that have been described to be associated with plaque transformation into a phenotype more exposed to rupture. These features include a large plaque burden $(\mathrm{PB})$, the presence of a large necrotic core (NC), positive remodeling (PR), the presence of napkin-ring sign (NR), spotty calcifications (SC), low density atheroma, the accumulation of macrophages, or a thin fibrous cap. ${ }^{11,12}$ All of these features have been demonstrated to be more present in lesions causing an acute coronary event as compared to more stable lesions, being also associated with a higher rate of major cardiac events. ${ }^{8,13-17}$

The complex process of atheromatous plaque vulnerabilization can be assessed by using invasive techniques such as intravascular ultrasound (IVUS) or optical coherence tomography (OCT), or by noninvasive techniques, mainly represented by computed tomography angiography (CTA). ${ }^{17-21}$

The current techniques of multislice CTA allow highquality noninvasive visualization of plaque features. A significant volume of plaque with low density, a high $\mathrm{PB}$, the presence of SC, active remodeling, and the NR sign inside the plaque have been identified as the main CTA-based characteristics associated with plaque vulnerability. ${ }^{13,17}$

Plaque vulnerability results from complex pathophysiological mechanisms that lead to changes in plaque structure and morphology. In unstable coronary arteries, the percentage of "unstable components", such as fatty tissue and NC, increase, while the amount of "stable components", such as fibrous tissue or calcified tissue, tend to decrease so that the fibrous cap becomes thinner and predisposed to rupture, triggering the sudden development of intra-coronary thrombosis and acute myocardial infarction. $3,4,13,22$

However, according to the authors' knowledge, the independent role of each plaque feature in relation to the others has not been clearly demonstrated and is still the subject of ongoing research. At the same time, the role of the anatomic location of the culprit lesions in favoring plaque vulnerabilization at this level has not been demonstrated so far.

The aim of the study was to compare the morphologic characteristics of vulnerable atheromatous coronary plaques with the ones of stable, non-vulnerable plaques (NVP) and of plaques with different locations in the coronary tree, in order to identify the most relevant imagingbased biomarkers associated with coronary plaque vulnerability.

\section{MATERIAL AND METHODS}

This was a prospective observational, non-randomized study including 50 patients with unstable angina who underwent CTA for assessment of the entire coronary artery tree, followed by the complex morphologic analysis of all coronary atherosclerotic lesions.

The inclusion criteria were: age over 18 years and diagnosis of unstable angina, defined as typical chest pain with ischemic ECG changes and no elevation of serum troponin. Patients with acute myocardial infarction were excluded from the study, as they were immediately referred to the cath lab for urgent revascularization. Patients with contraindication to contrast media administration and those with hemodynamic instability requiring intravenous inotropes were also excluded from the study.

\section{COMPUTED TOMOGRAPHY ANALYSIS}

Imaging acquisition was performed using a multislice 64 Somatom Sensation CT equipment (Siemens, Erlangen, Germany) with dynamic administration of $100 \mathrm{~mL}$ of contrast agent at a speed of $5 \mathrm{~mL} / \mathrm{s}$, followed by the administration of $100 \mathrm{~mL}$ of saline solution. All examinations were performed at a heart rate lower than 60 beats per minute. In patients with higher heart rates, intravenous beta blockers were administered to achieve the desired heart rate. Images obtained were analyzed using a 
dedicated software for quantification of plaque components: QAngioCT RE software (Medis, Leiden, The Netherlands), which allowed the quantification of different plaque features.

Lesion severity was estimated on the basis of degree of luminal narrowing, lesion length, luminal mean diameter, minimum luminal area, and plaque thickness.

The morphologic assessment included the calculation of plaque volume, mean plaque burden, plaque burden volume, remodeling index, and eccentricity index.

Plaque composition was assessed by the determination of NC, fibro-fatty tissue (FFT), fibrous tissue (FT), and dense calcium (DC), which were computed and calculated using both the volumetric method and the planimetric method at the site of maximum luminal narrowing.

\section{PLAQUE CLASSIFICATION AND STUDY GROUPS}

The classification of plaque type (vulnerable or non-vulnerable) was based on the assessment of classically described vulnerability features: low attenuation plaque, PR, the presence of SC, NR sign. Plaques which exhibited at least one feature of vulnerability were classified as VP, while plaques in which none of the above mentioned features was identified, were classified as NVP.

Culprit lesions, defined as the lesions responsible for causing the angina symptoms, were identified in correlation with the location of ischemia, which was assessed in correspondence with the location of ST segment/T wave changes on the surface ECG or the location of contractility disorders at the imaging stress test. Culprit lesions were defined as the coronary plaques located in the coronary segment that irrigates the ischemic area.
Patients were divided into two groups, according to the type of atheromatous plaque in the culprit lesion. Group 1 included 25 patients with vulnerable atheromatous plaque and group 2 included 25 age- and gender-matched patients with non-vulnerable atheromatous plaque.

\section{ETHICS}

The study protocol was conducted with the approval of the Ethics Committee of the institution, and all patients were informed about the purpose of the study and confidentiality of the data, and gave written informed consent. All study procedures have been carried out in accordance with the code of ethics of the World Medical Association's Declaration of Helsinki.

\section{STATISTICAL ANALYSIS}

Statistical analysis was performed using Graph Pad InStat 3.10 software (GraphPad Software, Inc., San Diego, USA). Continuous variables are presented as mean \pm standard deviation, while categorical variables are expressed as numbers and percentages. We used the unpaired Student's t-test for normally distributed continuous variables and the Mann-Whitney test for non-normally distributed continuous variables. The chi square exact test was used for comparison of categorical variables, and logistic regression analysis was performed to investigate the association between different features of VP and NVP in the culprit lesions. The statistical significance threshold was set at $\mathrm{p} \leq 0.05$, and all statistical tests were 2-sided.

TABLE 1. Baseline characteristics of the study groups

\begin{tabular}{|c|c|c|c|c|}
\hline & $\begin{array}{c}\text { Total } \\
(n=50)\end{array}$ & $\begin{array}{c}\text { Group 1 } \\
\operatorname{VP}(n=25)\end{array}$ & $\begin{array}{c}\text { Group } 2 \\
\text { NVP }(n=25)\end{array}$ & $\mathrm{p}$ value \\
\hline Age (years) & $61.68 \pm 11.53(58.40-64.96)$ & $63.76 \pm 11.39(59.06-68.46)$ & $59.60 \pm 11.52(54.84-64.36)$ & 0.41 \\
\hline Male gender $(\mathrm{n}, \%)$ & $37(74 \%)$ & $15(60 \%)$ & $22(88 \%)$ & 0.31 \\
\hline Hypertension (n, \%) & $35(70 \%)$ & $19(76 \%)$ & $16(64 \%)$ & 0.46 \\
\hline Dyslipidemia (n, \%) & $32(64 \%)$ & $15(60 \%)$ & $17(68 \%)$ & 0.62 \\
\hline Smoking status $(\mathrm{n}, \%)$ & $19(38 \%)$ & $14(56 \%)$ & $5(20 \%)$ & 0.34 \\
\hline Diabetes mellitus (n, \%) & $18(36 \%)$ & $7(28 \%)$ & $11(44 \%)$ & 0.32 \\
\hline Triglycerides (mg/dL) & $164.5 \pm 86.14(140.1-189.0)$ & $146.72 \pm 74.15(116.11-177.34)$ & $182 \pm 94.82(143.20-221.48)$ & 0.15 \\
\hline Total cholesterol (mg/dL) & $164.5 \pm 86.14(193.4-216.0)$ & $208.52 \pm 37.69(192.96-224.08)$ & $200.9 \pm 41.99(183.59-218.25)$ & 0.46 \\
\hline Creatinine (mg/dL) & $1.030 \pm 0.44(0.90-1.15)$ & $1.01 \pm 0.5(0.81-1.22)$ & $1.04 \pm 0.39(0.88-1.20)$ & 0.55 \\
\hline Urea (mg/dL) & $41.43 \pm 24.99(34.33-48.54)$ & $45.00 \pm 32.86(31.43-58.57)$ & $37.86 \pm 12.96(32.50-43.22)$ & 0.62 \\
\hline Glycemia (mg/dL) & $151.8 \pm 79.47(129.2-174.4)$ & $127.68 \pm 39.59(111.33-144.03)$ & $175.92 \pm 100.56(134.41-217.43)$ & 0.07 \\
\hline
\end{tabular}


TABLE 2. CT characteristics of vulnerable vs. non-vulnerable plaques in culprit lesions

\begin{tabular}{|c|c|c|c|c|}
\hline & $\begin{array}{c}\text { Total } \\
(n=50)\end{array}$ & $\begin{array}{c}\text { Group 1 } \\
\operatorname{VP}(n=25)\end{array}$ & $\begin{array}{c}\text { Group } 2 \\
\operatorname{NVP}(n=25)\end{array}$ & p value \\
\hline \multicolumn{5}{|l|}{ Lesion severity } \\
\hline Lesion length (mm) & $6.15 \pm 3.99(5.02-7.29)$ & $6.80 \pm 3.86(5.20-8.39)$ & $5.51 \pm 4.09(3.82-7.20)$ & 0.16 \\
\hline Lumen area $\left(\mathrm{mm}^{2}\right)$ & $57.81 \pm 18.22(52.63-62.98)$ & $58.49 \pm 18.51(50.85-66.13)$ & $57.11 \pm 18.28(49.57-64.66)$ & 0.79 \\
\hline Maximal Plaque Thickness (mm) & $2.66 \pm 0.85(2.42-2.91)$ & $3.05 \pm 0.91(2.67 \pm 3.42)$ & $2.28 \pm 0.59(2.03-2.52)$ & 0.001 \\
\hline \multicolumn{5}{|l|}{ Morphologic assessment } \\
\hline Plaque volume $\left(\mathrm{mm}^{3}\right)$ & $99.46 \pm 107.3(68.96-130.0)$ & $146.22 \pm 126.39(92.83-199.60)$ & $58.55 \pm 62.19(32.88-84.23)$ & 0.0005 \\
\hline Mean plaque burden (\%) & $70.38 \pm 9.66(67.63-73.12)$ & $74.99 \pm 8.74(71.38-78.60)$ & $65.75 \pm 8.35(62.31-69.20)$ & 0.0004 \\
\hline Necrotic core tissue volume $\left(\mathrm{mm}^{3}\right)$ & $28.68 \pm 41.74(16.82-40.54)$ & $54.52 \pm 46.46(35.34-73.70)$ & $2.72 \pm 2.54(1.78-3.88)$ & $<0.0001$ \\
\hline Fibrofatty tissue $\left(\mathrm{mm}^{3}\right)$ & $17.47 \pm 23.07(10.91-24.03)$ & $30.82 \pm 26.55(19.87-41.79)$ & $4.10 \pm 3.11(2.8-5.39)$ & $<0.0001$ \\
\hline Fibrotic tissue volume $\left(\mathrm{mm}^{3}\right)$ & $28.08 \pm 26.43(20.57-35.59)$ & $37.44 \pm 32.47(24.04-50.85)$ & $18.71 \pm 13.73(13.04-24.38)$ & 0.01 \\
\hline Dense calcium volume $\left(\mathrm{mm}^{3}\right)$ & $25.79 \pm 43.66(13.38-32.20)$ & $13.06 \pm 22.04(3.96-22.1)$ & $38.51 \pm 55.39(15.64-61.38)$ & 0.0007 \\
\hline \multicolumn{5}{|c|}{ Plaque components - planimetric assessment } \\
\hline Necrotic core area $\left(\mathrm{mm}^{2}\right)$ & $4.5 \pm 5.4(2.96-6.04)$ & $8.37 \pm 5.32(6.17-10.56)$ & $0.62 \pm 0.66(0.35-0.90)$ & $<0.0001$ \\
\hline Fibrofatty tissue area $\left(\mathrm{mm}^{2}\right)$ & $2.62 \pm 2.69(3.89-5.42)$ & $4.39 \pm 2.80(3.23-5.55)$ & $0.84 \pm 0.61(0.59-1.1)$ & $<0.0001$ \\
\hline Fibrotic tissue area $\left(\mathrm{mm}^{2}\right)$ & $4.65 \pm 2.68(3.89-5.42)$ & $5.52 \pm 3.27(4.17-6.87)$ & $3.79 \pm 1.57(3.13-4.44)$ & 0.02 \\
\hline Dense calcium area $\left(\mathrm{mm}^{2}\right)$ & $3.93 \pm 4.51(2.65-5.21)$ & $1.72 \pm 3.08(0.44-2.99)$ & $6.14 \pm 4.68(4.21-0.08)$ & $<0.0001$ \\
\hline
\end{tabular}

\section{RESULTS}

The general and biochemical characteristics of the study population are presented in Table 1. There were no statistically significant differences between the two study groups in relation to age $(\mathrm{p}=0.4)$, gender $(\mathrm{p}=0.3)$, cardiovascular risk factors: smoking status $(\mathrm{p}=0.3)$, hypertension ( $\mathrm{p}=0.4)$, obesity $(\mathrm{p}=0.2)$, dyslipidemia $(\mathrm{p}=0.6)$, and serum levels of triglycerides $(\mathrm{p}=0.1)$, total cholesterol $(\mathrm{p}=0.4)$, creatinine $(\mathrm{p}=0.5)$, and urea $(\mathrm{p}=0.6)$. Interestingly, patients with NVP had a higher frequency of diabetes ( $44 \%$ vs. $28 \%, p=0.3$ ) and had higher levels of fasting glucose than group $1(127.68 \pm 39.59 \mathrm{mg} / \mathrm{dL}$ vs. $175.92 \pm$ $100.56 \mathrm{mg} / \mathrm{dL}, \mathrm{p}=0.07$ ), but these differences were not statistically significant.

\section{SEVERITY OF CULPRIT CORONARY LESIONS}

The results of CTA analysis are presented in Table 2. CT analysis post-processing did not reveal any significant difference between VP and NVP in respect to the severity of stenosis and the length of the lesion, both types exhibiting a similar anatomic pattern $(p=0.7$ for degree of stenosis and $\mathrm{p}=0.1$ for lesion length) (Figure 1A). However, lesions with a stenosis degree $>70 \%$ were significantly longer than those with a stenosis degree $<70 \%(8.27 \pm 2.74 \mathrm{~mm}$ vs. $5.56 \pm 4.11 \mathrm{~mm}, \mathrm{p}=0.04$ ) (Figure $1 \mathrm{~B}$ ). Luminal area and intraluminal maximum diameter were also not significantly different between the two groups ( $p=0.7$ for both).

Despite the similar degree of anatomic severity, VP presented significantly higher values of plaque thickness. Both minimal and maximal thickness of the culprit VP were significantly higher than the ones of NVP ( $0.77 \pm 0.59 \mathrm{~mm}$ vs. $0.29 \pm 0.34 \mathrm{~mm}, \mathrm{p}=0.0005$ for minimal plaque thickness and $3.05 \pm 0.91 \mathrm{~mm}$ vs. $2.28 \pm 0.59 \mathrm{~mm}$, $\mathrm{p}=0.001$ for maximal plaque thickness).

\section{MORPHOLOGIC CHARACTERISTICS OF CULPRIT CORONARY PLAQUES}

Compared to non-vulnerable coronary lesions, vulnerable coronary plaques presented significantly larger atheromatous burden than non-vulnerable ones. The mean plaque burden was $74.9 \pm 8.7 \%$ in group 1 and $65.7 \pm$ $8.3 \%$ in group $2(\mathrm{p}=0.0004)$, while the total plaque vol- 
A
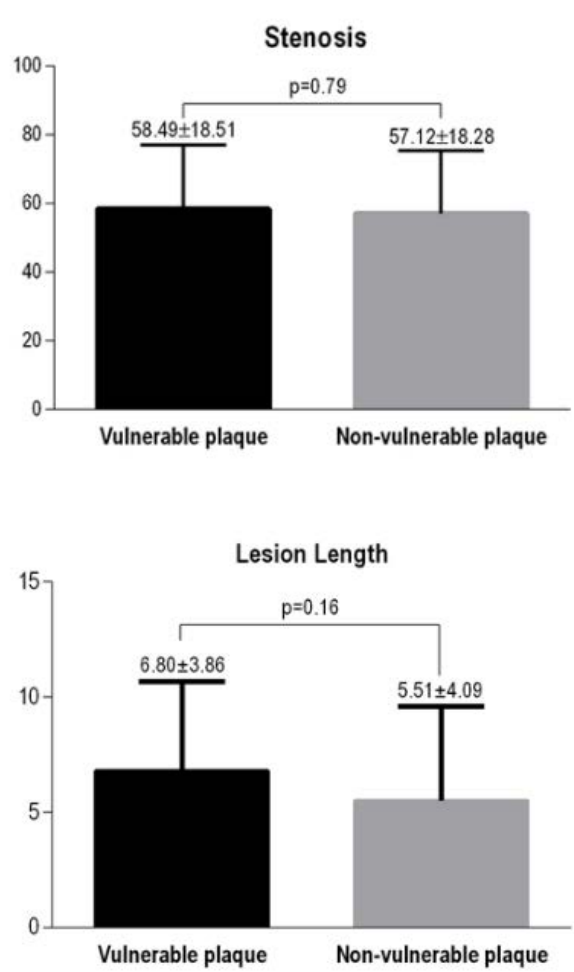

B

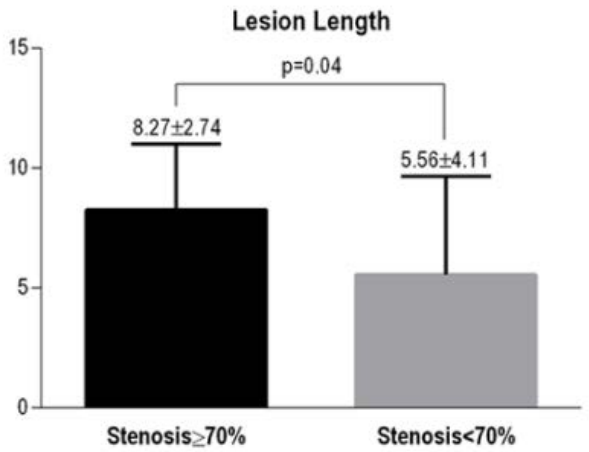

FIGURE 1. Severity of culprit lesions in coronary atheromatous plaques
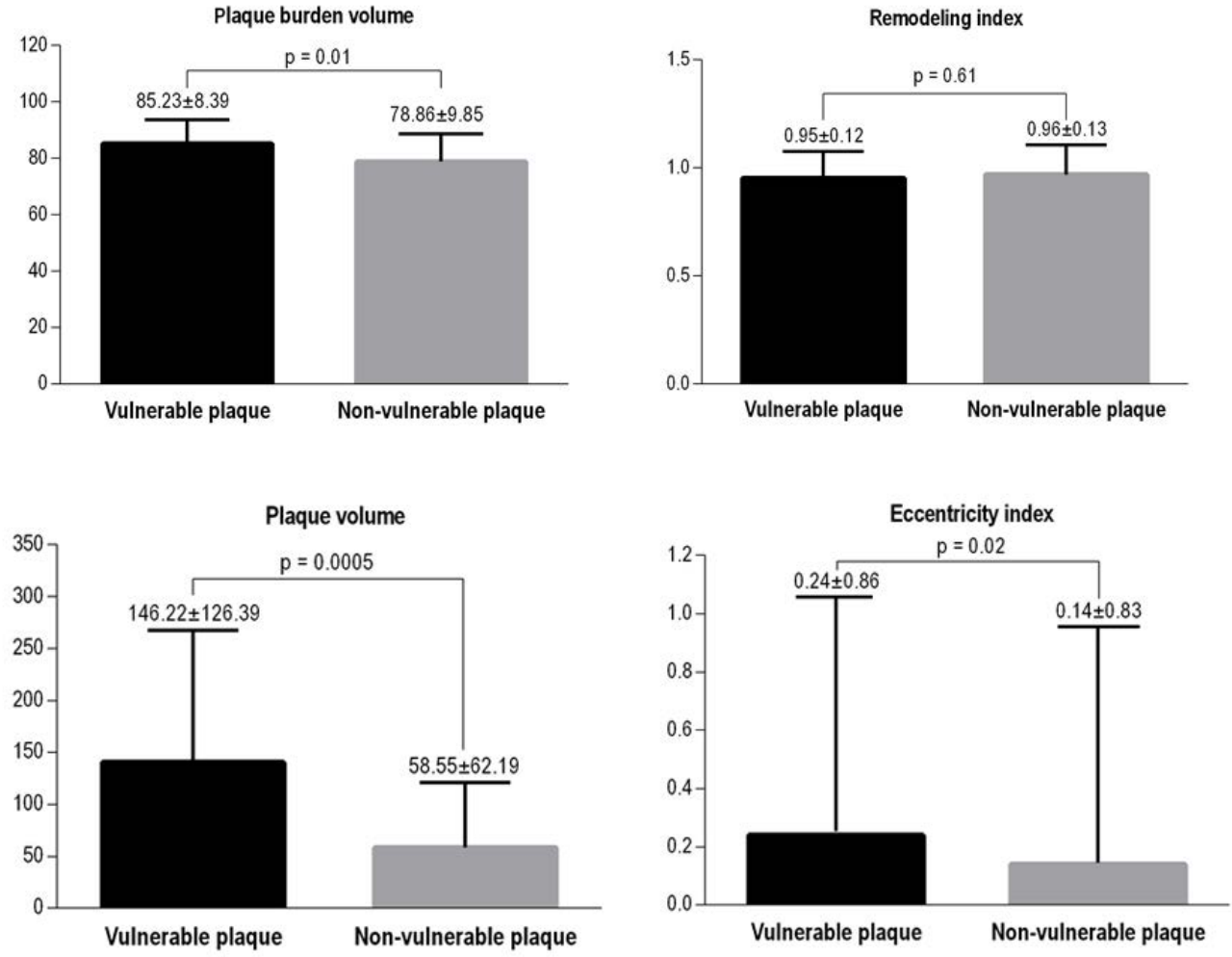

FIGURE 2. Morphologic characteristics of culprit lesions in vulnerable vs non-vulnerable coronary plaques 
A


B
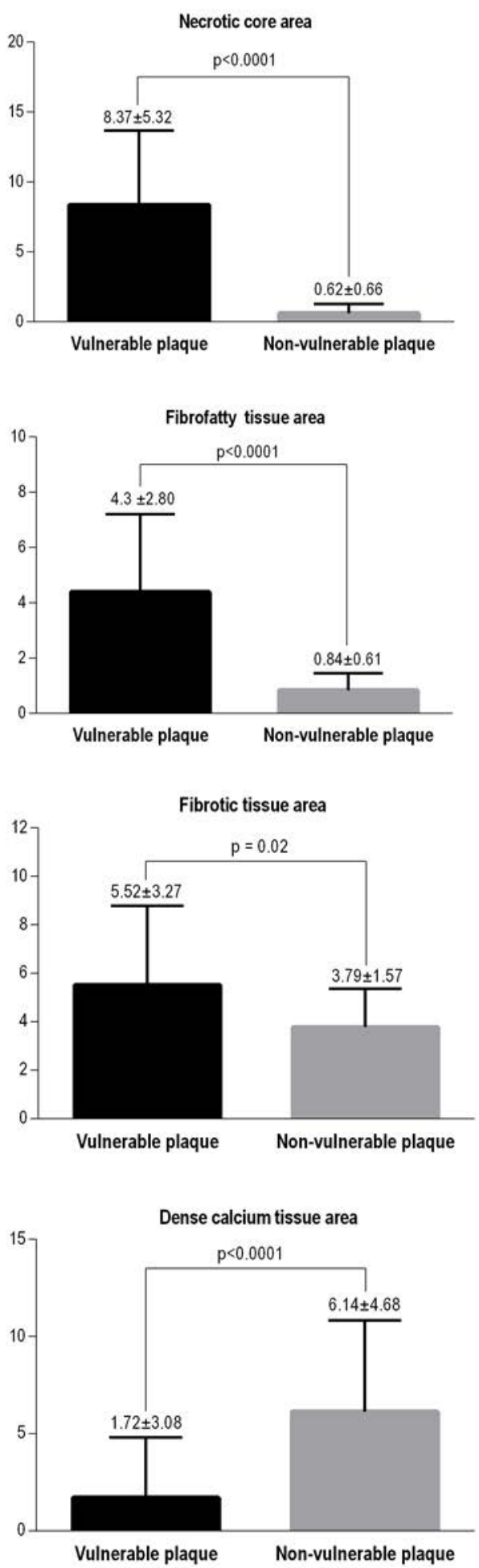

FIGURE 3. Plaque components in culprit lesions. A - volumetric assessment; B - planimetric assessment

ume was almost three times higher in VP than in NVP $\left(146.2 \pm 126.3 \mathrm{~mm}^{3}\right.$ vs. $\left.58.5 \pm 62.1 \mathrm{~mm}^{3}, \mathrm{p}=0.0005\right)$. Interestingly, the remodeling index was not significantly different between the groups ( $p=0.6$ ), but the eccentricity index was ( $0.24 \pm 0.14$ compared to $0.14 \pm 0.17$, p $=0.023$ ) (Figure 2 ). 
A
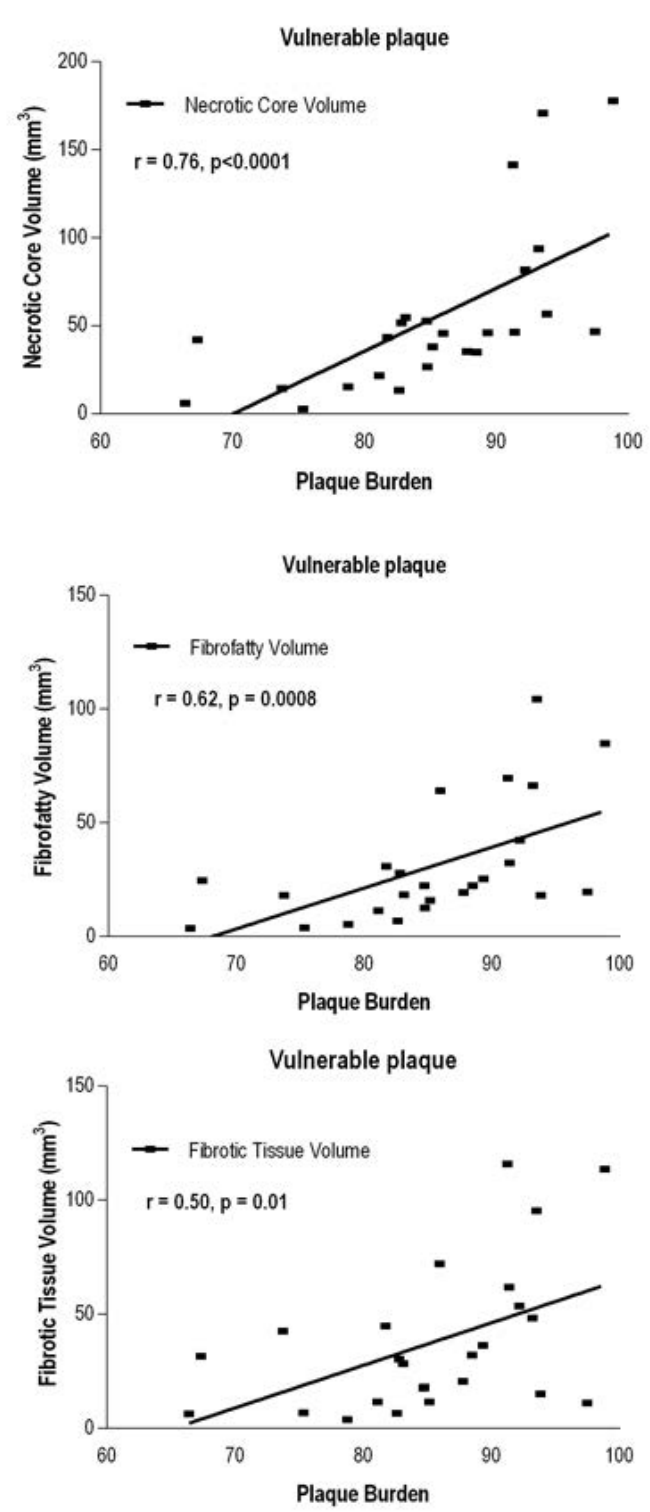

B
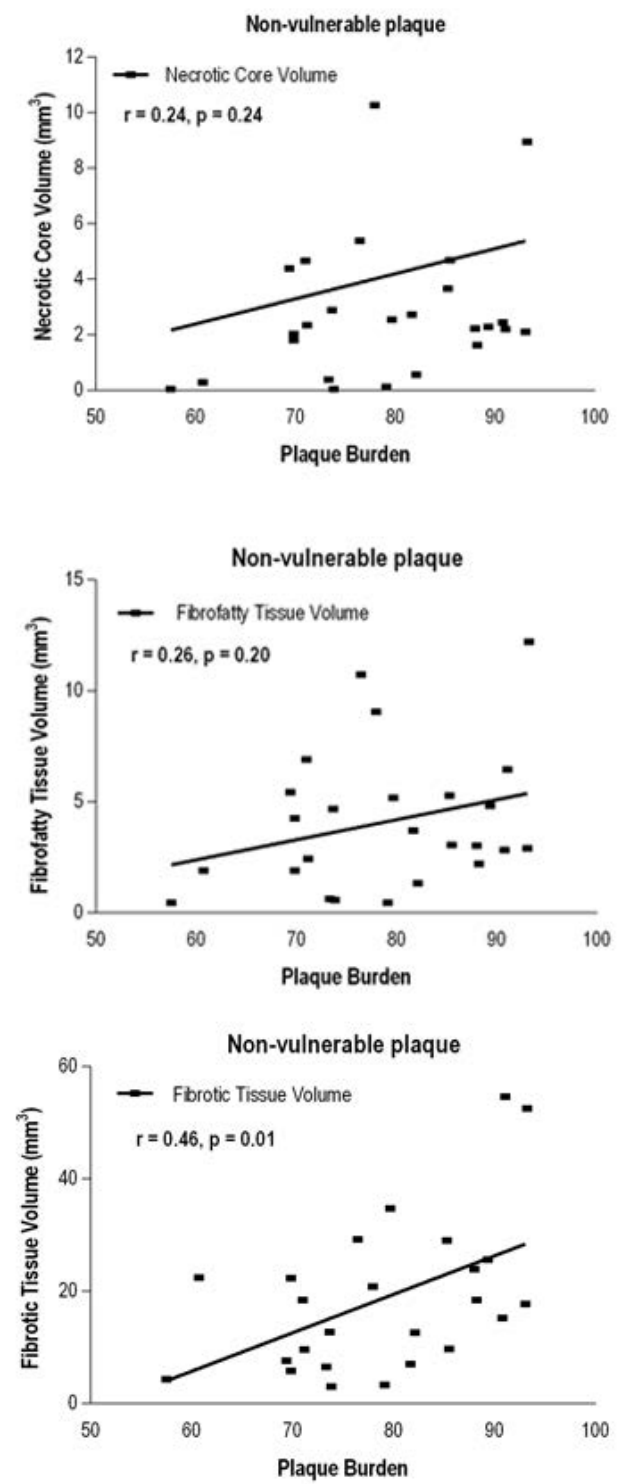

FIGURE 4. Correlation between total plaque burden and several plaque components in vulnerable plaques (A) and non-vulnerable plaques (B)

The most significant difference between the study groups was recorded in relation to plaque components. Compared to plaques without features of vulnerability, VP exhibited significantly larger volumes of NC (20 times higher than non-vulnerable ones), FFT (7 times higher than non-vulnerable ones), and FT volumes (2 times higher than non-vulnerable ones). Opposite, the amount of DC volume was significantly higher in NVP ( $p=0.0007$ for DC volume and $\mathrm{p}<0.0001$ for DC area) (Figure 3 ).

Linear regression analysis revealed a significant correlation between plaque burden and plaque components in VP ( $\mathrm{r}=0.76, \mathrm{p}<0.0001$ for NC; $\mathrm{r}=0.62, \mathrm{p}=0.0008$ for FFT; and $\mathrm{r}=0.5, \mathrm{p}=0.01$ for FT volume). However, this correlation was not relevant for NVP $(r=0.24, p=0.2$ for $\mathrm{NC} ; \mathrm{r}=0.26, \mathrm{p}=0.2$ for FFT; and $\mathrm{r}=0.46, \mathrm{p}=0.01$ for FT volume) (Figure 4).

\section{ANATOMIC CHARACTERISTICS OF CULPRIT ATHEROMATOUS PLAQUES}

Culprit plaques located in the right coronary artery presented significantly larger plaque burden volumes 
TABLE 3. CT characteristics of vulnerable plaques in right vs. left coronary artery

\begin{tabular}{|c|c|c|c|c|}
\hline \multicolumn{5}{|l|}{ Lesion severity } \\
\hline Lesion length (mm) & $6.80 \pm 3.86(5.20-8.39)$ & $8.08 \pm 3.65(4.25-11.92)$ & $6.39 \pm 3.93(4.49-8.29)$ & 0.36 \\
\hline Lumen area $\left(\mathrm{mm}^{2}\right)$ & $58.49 \pm 18.51(50.85-66.14)$ & $70.89 \pm 10.94(59.41-82.37)$ & $54.58 \pm 18.88(45.48-63.88)$ & 0.05 \\
\hline Maximal Plaque Thickness (mm) & $3.05 \pm 0.91(2.67-3.42)$ & $3.33 \pm 0.52(2.78-3.89)$ & $2.96 \pm 1.0(2.47-3.44)$ & 0.15 \\
\hline \multicolumn{5}{|l|}{ Morphologic assessment } \\
\hline Plaque volume $\left(\mathrm{mm}^{3}\right)$ & $140.4 \pm 127.1(87.89-192.8)$ & $206.2 \pm 112.4(88.27-324.2)$ & $119.16 \pm 127.0(58.33-180.8)$ & 0.05 \\
\hline Mean plaque burden (\%) & $75.0 \pm 8.74(71.39-78.60)$ & $80.64 \pm 9.09(71.09-90.18)$ & $73.21 \pm 8.05(69.33-77.10)$ & 0.06 \\
\hline Necrotic core tissue volume $\left(\mathrm{mm}^{3}\right)$ & $54.53 \pm 46.47(35.35-73.71)$ & $82.03 \pm 47.85(31.81-132.2)$ & $45.84 \pm 43.72(24.77-66.92)$ & 0.02 \\
\hline Fibrofatty tissue $\left(\mathrm{mm}^{3}\right)$ & $30.83 \pm 26.55(19.87-41.79)$ & $53.23 \pm 31.92(19.73-86.73)$ & $23.76 \pm 20.90(13.69-33.83)$ & 0.02 \\
\hline Fibrotic tissue volume $\left(\mathrm{mm}^{3}\right)$ & $37.45 \pm 32.48(24.04-50.85)$ & $49.64 \pm 32.0(16.06-83.22)$ & $33.60 \pm 35.51(17.93-49.27)$ & 0.22 \\
\hline Dense calcium volume $\left(\mathrm{mm}^{3}\right)$ & $13.07 \pm 22.05(3.96-22.17)$ & $8.48 \pm 11.48(-3.55-20.53)$ & $14.51 \pm 24.54(2.68-26.34)$ & 0.43 \\
\hline \multicolumn{5}{|c|}{ Plaque components - planimetric assessment } \\
\hline Necrotic core area $\left(\mathrm{mm}^{2}\right)$ & $8.37 \pm 5.32(6.17-10.57)$ & $13.07 \pm 4.29(8.57-11.57)$ & $6.88 \pm 4.78(4.57-9.19)$ & 0.009 \\
\hline Fibrofatty tissue area $\left(\mathrm{mm}^{2}\right)$ & $4.39 \pm 2.80(3.23-5.55)$ & $7.22 \pm 3.81(3.22-11.22)$ & $3.50 \pm 1.72(2.67-4.33)$ & 0.002 \\
\hline Fibrotic tissue area $\left(\mathrm{mm}^{2}\right)$ & $5.52 \pm 3.27(4.17-6.87)$ & $5.21 \pm 2.58(2.50-7.93)$ & $5.62 \pm 3.51(3.92-7.31)$ & 0.79 \\
\hline Dense calcium area $\left(\mathrm{mm}^{2}\right)$ & $1.94 \pm 3.15(0.64-3.24)$ & $2.21 \pm 3.49(-1.45-5.88)$ & $1.85 \pm 3.13(0.34-3.37)$ & 0.65 \\
\hline
\end{tabular}

than those located in the left coronary artery (91.17 \pm $4.88 \mathrm{~mm}^{3}$ vs. $\left.83.35 \pm 8.47 \mathrm{~mm}^{3}, \mathrm{p}=0.04\right)$. At the same time, culprit plaques located in the right coronary artery exhibited larger volumes of NC $\left(82.03 \pm 47.85 \mathrm{~mm}^{3}\right.$ vs. $\left.45.84 \pm 43.72 \mathrm{~mm}^{3}, \mathrm{p}=0.02\right)$ and FFT $\left(53.23 \pm 31.92 \mathrm{~mm}^{3}\right.$ vs. $\left.23.76 \pm 20.90 \mathrm{~mm}^{3}, \mathrm{p}=0.02\right)$ than the ones situated in the left coronary artery (Table 3 ). The remodeling index was not significantly different between the two coronary artery lesions $(p=0.7)$, but the eccentricity index was $(0.37 \pm 0.85$ compared to $0.20 \pm 0.89, p=0.007)$ (Figure 5).

\section{DISCUSSION}

The composition of an atheromatous plaque plays a crucial role in the complex process of plaque progression and vulnerabilization. In an IVUS-based analysis, the PROSPECT study clearly demonstrated that the most powerful predictor of future cardiac events is represented by the atheromatous plaque burden. ${ }^{23}$ However, plaque progression is difficult to evaluate using IVUS, due to the invasive nature of this investigation. CTA could represent an effective tool for the repeated assessment of plaque composi- tion and for assessing the progression of lesion severity as well, using a noninvasive route.

Once the CTA examination identifies a VP, different strategies can be initiated in order to reduce plaque progression. Such strategies include lesion revascularization via coronary stenting in case of significant lesions, or statin therapy for non-significant lesions. The infusion of mononuclear cells at the site of the VP has been also proposed as an experimental method aiming to stabilize the plaque and prevent its progression. ${ }^{24}$

It became obvious that in case of VPs, a therapeutic decision should be based on a complex assessment of both plaque composition and lesion severity, while CTA is the golden standard imaging technology for performing such a complex evaluation in one single step.

In this study, we did not find a significant difference between the study groups in respect to lesion severity, VPs and NVPs having similar lengths, area and diameters. However, plaque thickness was significantly higher in VPs.

Morphologic assessment has identified significantly different phenotypes of atheromatous plaque in VP versus NVP ones, showing that VPs have larger volumes and ar- 

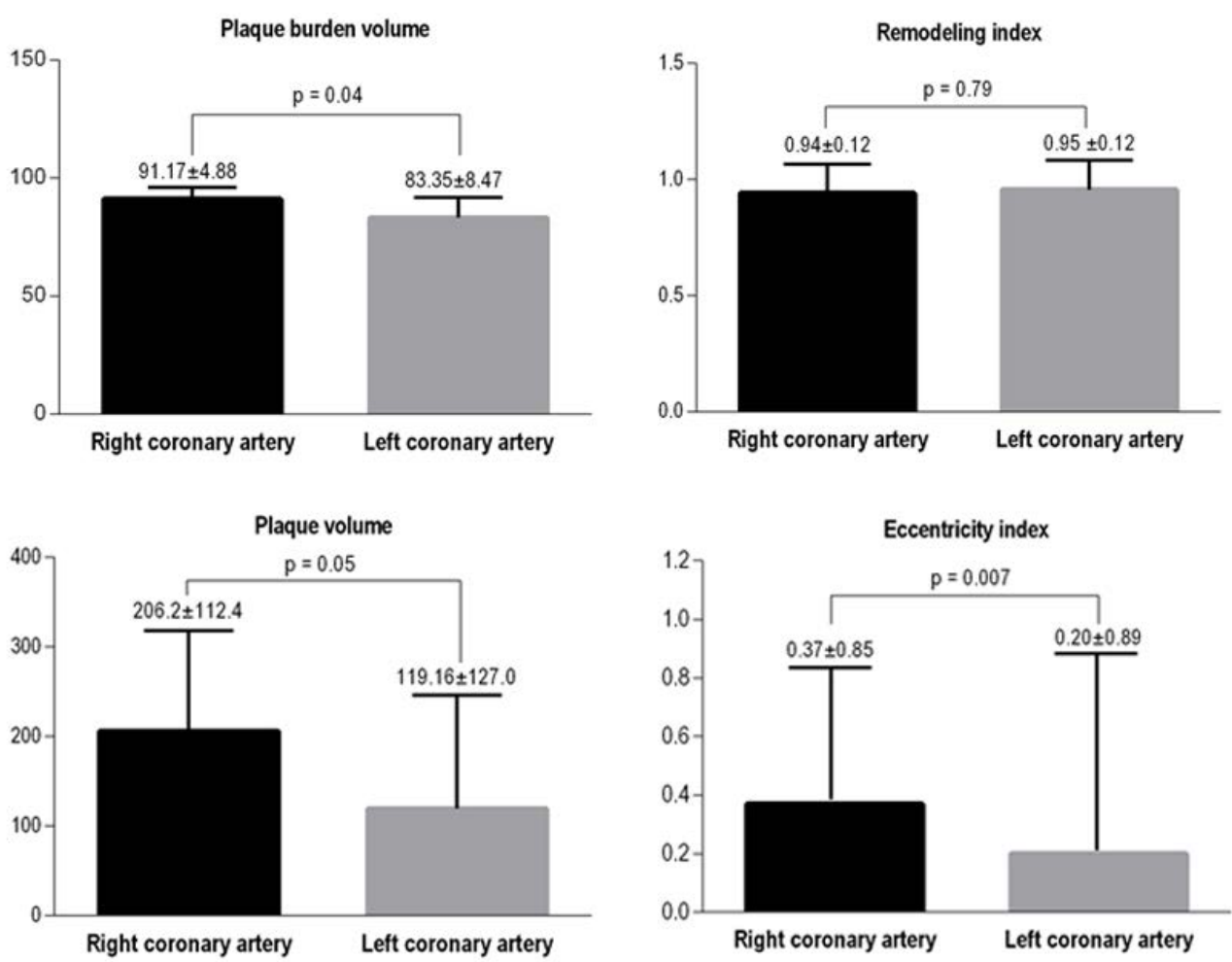

FIGURE 5. Characteristics of culprit vulnerable plaques according to their anatomical distribution

eas at the level of the minimum stenosis, and significantly higher eccentricity.

IVUS studies have identified and validated various imaging-based features of plaque composition and conformation that are associated with plaque vulnerability. Studies conducted by Maejima et al. and Kato et al. showed that increased plaque burden, higher plaque volume, and RI are associated with plaque vulnerability, similarly with results obtained by Okubo et al., which identified that significantly increased volumes of plaque burden, FFT, FT, and NC represent imaging-based biomarkers for predicting plaque vulnerability. ${ }^{25-27}$

Almost all the features classically defined by IVUS studies as associated with plaque vulnerability were present in a significantly higher extent in VPs, in this CTA-based study: plaque volume, NC volume, and the amount of FFT. The amount of DC inside the plaque was, on the contrary, significantly higher in NVPs, perhaps providing a protective effect against rupture or erosion.

PR represents a classical marker of plaque vulnerability, as described in studies conducted by Finn et al. and Burke et al., suggesting that PR may be a potential surrogate marker in detecting lesion vulnerability, results also demonstrated by Pasterkamp et al.4,28-30 However, in our study, this was not significantly different between the VPs and NVPs, and in fact, the average value of RI in VPs was not high. This could be explained by the fact that a large proportion of the study population included diabetics, known to exhibit the opposite phenomenon of negative remodeling, which could have compensated the vulnerability-dependent PR.

One of the most interesting findings of the study is that the anatomic distribution of coronary plaques in the coronary tree could influence the degree of vulnerability. Lesions located in the right coronary artery presented larger plaques, with higher volume and plaque burden than those located in the left coronary artery, at the same time exhibiting a higher degree of stenosis (70.89 \pm 10.94 vs. $54.58 \pm 18.88, p=0.05)$, but non-significant differences in plaque lengths. However, our study has identified significantly higher values of main vulnerability features (NC volume and area, and FFT volume and area), in parallel with a more expressed eccentricity at the level of right coronary artery lesions. The fact that right coronary lesions present larger volumes and larger amounts of intracoronary thrombi has been described by other studies..$^{31-35}$ However, according to our knowledge, this is the first study describing a clear difference of vulnerability features in relation to anatomic location in the left versus right coronary tree, suggesting that the right coronary artery is more predisposed to the vulnerabilization process of the atheromatous plaques, which can 
occur in time during the development of plaque progression mechanisms.

\section{CONCLUSIONS}

Morphologic assessment using both volumetric and planimetric methods showed that in patients with coronary atherosclerosis and unstable angina, vulnerable atheromatous plaques from the culprit lesions exhibit a different phenotype than non-vulnerable ones. Vulnerability features are present in a significantly larger extent in VPs from culprit lesions, at the same time being more pronounced in lesions from the right coronary artery as compared to the left one.

\section{CONFLICT OF INTEREST}

None to declare.

\section{ACKNOWLEDGEMENT}

This research was supported via the research grant no. 103544/2016 - PLaqueIMAGE, contract number 26/01.09.2016, financed by the Romanian Ministry of European Funds, the Romanian Government, and the European Union.

\section{REFERENCES}

1. World Health Organisation, Cardiovascular disease (CVDs), 2016. Available from: http://www.who.int/mediacentre/ factsheets/fs317/en/\#.

2. Dubey G, Verma SK, Bahl VK. Primary percutaneous coronary intervention for acute ST elevation myocardial infarction: Outcomes and determinants of outcomes: A tertiary care center study from North India. Indian Heart J. 2017;69:294298. doi: 10.1016/j.ihj.2016.11.322.

3. Choy SY, Mintz GS. What have we learned about plaque rupture in acute coronary syndromes? Curr Cardiol Rep. 2010;12:338343. doi: 10.1007/s11886-010-0113-x.

4. Finn AV, Nakano M, Narula J, Kolodgie FD, Virmani R. Concept of vulnerable/unstable plaque. Arterioscler Thromb Vasc Biol. 2010;30:1282-1292. doi: 10.1161/ATVBAHA.108.179739.

5. Stone GW, Maehara A, Lansky AJ, et al. A prospective naturalhistory study of coronary atherosclerosis. N Engl J Med. 2011;364:226-235. doi: 10.1056/NEJMoa1002358.

6. Bentzon JF, Otsuka F, Virmani R, Falk E. Mechanisms of plaque formation and rupture. Circ Res. 2014;114:1852-1866. doi: 10.1161/CIRCRESAHA.114.302721.

7. Stefanadis C, Antoniou CK, Tsiachris D, Pietri P. Coronary Atherosclerotic Vulnerable Plaque: Current Perspectives. J Am Heart Assoc. 2017;6:e005543. doi: 10.1161/JAHA.117.005543.

8. Benedek T, Gyöngyösi M, Benedek I. Multislice Computed Tomographic Coronary Angiography for Quantitative
Assessment of Culprit Lesions in Acute Coronary Syndromes. Can J Cardiol. 2013;29:364-371. doi: 10.1016/j.cjca.2012.11.004.

9. Giblett JP, Brown AJ, Keevil H, Jaworski C, Hoole SP, West NE. Implantation of bioresorbable vascular scaffolds following acute coronary syndrome is associated with reduced early neointimal growth and strut coverage. EuroIntervention. 2016;12:724-733. doi: 10.4244/EIJV12I6A117.

10. Giannakopoulos TG, Avgerinos ED, Moulakakis KG, et al. Biomarkers for diagnosis of the vulnerable atherosclerotic plaque. Interv Cardiol. 2011;3;223-233.

11. Dalager MG, Bøttcher M, Thygesen J, Andersen G, Bøtker HE. Different Plaque Composition and Progression in Patients with Stable and Unstable Coronary Syndromes Evaluated by Cardiac CT. BioMed Research International. 2015;2015:401357. doi:10.1155/2015/401357.

12. Waxman S, Ishibashi F, Muller JE. Detection and Treatment of Vulnerable Plaques and Vulnerable Patients. Novel Approaches to Prevention of Coronary Events. Circulation. 2006;114:23902411. doi: 10.1161/CIRCULATIONAHA.105.540013.

13. Maurovich-Horvat P, Schlett CL, Alkadhi H, et al. The napkin-ring sign indicates advanced atherosclerotic lesions in coronary CT angiography. JACC Cardiovasc Imaging. 2012;5:1243-1252. doi: 10.1016/j.jcmg.2012.03.019.

14. Kajander OA, Pinilla-Echeverri N, Jolly SS, et al. Culprit plaque morphology in STEMI - an optical coherence tomography study: insights from the TOTAL-OCT substudy. EuroIntervention. 2016;12:716-723. doi: 10.4244/EIJV12I6A116. 15. White SJ, Newby AC, Johnson TW. Endothelial erosion of plaques as a substrate for coronary thrombosis. Thromb Haemost. 2016;115:509-519. doi: 10.1160/TH15-09-0765.

16. Nasu K, Tsuchikane E, Katoh O, et al. Accuracy of in vivo coronary plaque morphology assessment: a validation study of in vivo virtual histology compared with in vitro histopathology. J Am Coll Cardiol. 2006;47:2405-2412. doi: 10.1016/j.jacc.2006.02.044.

17. Motoyama S, Masayoshi S, Harigaya H, et al. Computed tomographic angiography characteristics of atherosclerotic plaques subsequently resulting in acute coronary syndrome. J Am Coll Cardiol. 2009;54:49-57. doi: 10.1016/j. jacc.2009.02.068.

18. Tian J, Ren X, Vergallo R, et al. Distinct morphological features of ruptured culprit plaque for acute coronary events compared to those with silent rupture and thin-cap fibroatheroma: a combined optical coherence tomography and intravascular ultrasound study. J Am Coll Cardiol. 2014;63:2209-2216. doi: 10.1016/j.jacc.2014.01.061.

19. Jang IK. Optical Coherence Tomography or Intravascular Ultrasound? JACC: Cardiovascular Interventions. 2011;4:492494. doi: 10.1016/j.jcin.2011.02.004.

20. Yonetsu T, Lee T, Murai T, et al. Plaque morphologies and the clinical prognosis of acute coronary syndrome caused by lesions with intact fibrous cap diagnosed by optical coherence tomography. Int J Cardiol. 2016;203:766-774. doi: 10.1016/j. ijcard.2015.11.030

21. Benedek T, Jako B, Benedek I. Plaque quantification by coronary $\mathrm{CT}$ and intravascular ultrasound identifies a low CT density core as a marker of plaque instability in acute coronary syndromes. Int Heart J. 2014;55:22-28. doi.org/10.1536/ihj.13-213.

22. Ohayon J, Finet G, Gharib AM, et al. Necrotic core thickness and positive arterial remodeling index: emergent biomechanical factors for evaluating the risk of plaque rupture. Am J Physiol 
Heart Circ Physiol. 2008;295:H717-H727. doi.org/10.1152/ ajpheart.00005.2008

23. Xie Y, Mintz G, Yang J, et al. Clinical Outcome of Nonculprit Plaque Ruptures in Patients with Acute Coronary Syndrome in the PROSPECT Study. JACC Cardiovasc Imaging. 2014;7:397405. doi: 10.1016/j.jcmg.2013.10.010.

24. Benedek I, Bucur O, Benedek T. Intracoronary infusion of mononuclear bone marrow-derived stem cells is associated with a lower plaque burden after four years. J Atheroscler Thromb. 2014;21:217-229. doi.org/10.5551/jat.19745.

25. Maejima N, Hibi K, Saka K, et al. Morphological features of non-culprit plaques on optical coherence tomography and integrated backscatter intravascular ultrasound in patients with acute coronary syndromes. Eur Heart J Cardiovasc Imaging. 2015;16:190-197. doi: 10.1093/ehjci/jeu173.

26. Kato M, Dote K, Sasaki S, et al. Presentations of acute coronary syndrome related to coronary lesion morphologies as assessed by intravascular ultrasound and optical coherence tomography. Int J Cardiol. 2013;165:506-511. doi: 10.1016/j. ijcard.2011.09.032.

27. Okubo M, Kawasaki M, Ishihara Y, et al. Tissue characterization of coronary plaques: comparison of integrated backscatter intravascular ultrasound with virtual histology intravascular ultrasound. Circ J. 2008;72:1631-1639. doi.org/10.1253/circj. CJ-07-0936.

28. Burke AP, Kolodgie FD, Farb A, Weber D, Virmani R. Morphological predictors of arterial remodeling in coronary atherosclerosis. Circulation. 2002;105:297-303. doi: https:// doi.org/10.1161/hc0302.102610
29. Pasterkamp G, Schoneveld AH, van der Wal AC, et al. Relation of arterial geometry to luminal narrowing and histologic markers for plaque vulnerability: the remodeling paradox. J Am Coll Cardiol. 1998;32:655-662. doi: 10.1016/S07351097(98)00304-0.

30. Tian J, Ren X, Vergallo R, et al. Distinct Morphological Features of Ruptured Culprit Plaque for Acute Coronary Events Compared to Those With Silent Rupture and Thin-Cap Fibroatheroma. A Combined Optical Coherence Tomography and Intravascular Ultrasound Study. JACC. 2014;63:22092216. doi.org/10.1016/j.jacc.2014.01.061.

31. Lee Y, Kim E, Kim BK, Shin JH. A case of successful reperfusion through a combination of intracoronary thrombolysis and aspiration thrombectomy in ST segment elevation myocardial infarction associated with an ectatic coronary artery. BMC Cardiovascular Disorders. 2017;17:94. doi.org/10.1186/s12872017-0527-0.

32. Carey BC, Blankenship JC. A Sequential Approach to the Management of a Massive Intracoronary Thrombus in ST Elevation Myocardial Infarction: A Case Report. 2007;58:106111. doi: https://doi.org/10.1177/0003319706295511.

33. Kang SJ, Nakano M, Virmani R, et al. OCT Findings in Patients With Recanalization of Organized Thrombi in Coronary Arteries. JACC: Cardiovascular Imaging. 2012;5:725732. doi: https://doi.org/10.1016/j.jcmg.2012.03.012.

34. Benedek T, Bucur O, Pascanu I, Benedek I. Analysis of coronary plaque morphology by 64-multislice computed tomography coronary angiography and calcium scoring in patients with type 2 diabetes mellitus. Acta Endocrinologica. 2011;7:59-68. doi: https://doi.org/10.4183/aeb.2011.59. 